\title{
Conventional surgery, sutureless valves, and transapical aortic valve replacement: What is the best option for patients with aortic valve stenosis? A multicenter, propensity-matched analysis
}

\author{
Augusto D'Onofrio, MD, ${ }^{\mathrm{a}}$ Giulio Rizzoli, MD, ${ }^{\mathrm{a}}$ Antonio Messina, MD, PhD, ${ }^{\mathrm{b}}$ Ottavio Alfieri, MD, \\ Roberto Lorusso, MD, PhD, ${ }^{\mathrm{d}}$ Stefano Salizzoni, MD ${ }^{\mathrm{e}}$ Mattia Glauber, MD, ${ }^{\mathrm{f}}$ Roberto Di Bartolomeo, MD, ${ }^{\mathrm{g}}$ \\ Laura Besola, MD, ${ }^{a}$ Mauro Rinaldi, MD, ${ }^{\mathrm{e}}$ Giovanni Troise, $\mathrm{MD},{ }^{\mathrm{b}}$ and Gino Gerosa, $\mathrm{MD}^{\mathrm{a}}$
}

\begin{abstract}
Objective: Although surgical aortic valve replacement (SAVR) is the treatment of choice for patients with aortic valve stenosis, transcatheter aortic valve replacement (TAVR) and sutureless aortic valve replacement (SU-AVR) have shown good results. The aim of our multicenter, propensity-matched study was to compare the clinical and hemodynamic outcomes of surgical SAVR, transapical TAVR (TA-TAVR), and SU-AVR.
\end{abstract}

\begin{abstract}
Methods: We analyzed data from 566 TA-TAVR, 349 SAVR, and 38 SU-AVR patients treated from January 2009 to March 2012. We used a propensity-matching strategy to compare on-pump (SAVR, SU-AVR) and off-pump (TA-TAVR) surgical techniques. The outcomes were analyzed using multivariate weighted logistic regression or multinomial logistic analysis.
\end{abstract}

Results: In the matched cohorts, the 30-day overall mortality was significantly lower after SAVR than TA-TAVR $(7 \%$ vs $1.8 \%, P=.026)$, with no differences in mortality between SU-AVR and TA-TAVR. Multivariate analysis showed SU-AVR to have a protective effect, although not statistically significant, against aortic regurgitation, pacemaker implantation, and renal replacement therapy compared with TA-TAVR. Compared with TA-TAVR, SAVR demonstrated significant protection against aortic regurgitation (odds ratio, 0.04; $P<.001)$ and a trend toward protection against death, pacemaker implantation, and myocardial infarction. The mean transaortic gradient was $10.3 \pm 4.4 \mathrm{~mm} \mathrm{Hg}, 11 \pm 3.4 \mathrm{~mm} \mathrm{Hg}$, and $16.5 \pm 5.8 \mathrm{~mm} \mathrm{Hg}$ in the TA-TAVR, SU-AVR, and SAVR patients, respectively.

Conclusions: SAVR was associated with lower 30-day mortality than TA-TAVR. SAVR was also associated with a lower risk of postoperative aortic regurgitation compared with TA-TAVR. We did not find other significant differences in outcomes among matched patients treated with SAVR, SU-AVR, and TA-TAVR. (J Thorac Cardiovasc Surg 2013;146:1065-71)

Surgical aortic valve replacement (SAVR) is the treatment of choice in patients with severe symptomatic aortic valve stenosis (SSAVS). The results of SAVR are reproducible and well established, and its complications are known. ${ }^{1}$ However, in the past few years, new alternative therapeutic strategies have been introduced into clinical practice with high

\footnotetext{
From the Division of Cardiac Surgery, ${ }^{\text {a }}$ University of Padova, Padova, Italy; Division of Cardiac Surgery, ${ }^{\mathrm{b}}$ Poliambulanza Hospital, Brescia, Italy; Department of Cardiac Surgery, ${ }^{c}$ San Raffaele University Hospital, Milan, Italy; Cardiac Surgery Unit, ${ }^{\mathrm{d}}$ Community Hospital, Brescia, Italy; Division of Cardiac Surgery, ${ }^{\mathrm{e}}$ University of Turin, Turin, Italy; Department of Adult Cardiac Surgery, ${ }^{\mathrm{f}}$ G. Pasquinucci Heart Hospital, Massa, Italy; and Division of Cardiac Surgery, ${ }^{\mathrm{g}}$ University of Bologna, Bologna, Italy.

Disclosures: Authors have nothing to disclose with regard to commercial support.

Read at the 93rd Annual Meeting of The American Association for Thoracic Surgery, Minneapolis, Minnesota, May 4-8, 2013.

Received for publication April 19, 2013; revisions received June 11, 2013; accepted for publication June 26, 2013; available ahead of print Sept 9, 2013.

Address for reprints: Augusto D'Onofrio, MD, Division of Cardiac Surgery, University Hospital Centro Gallucci, Via Giustiniani 2, Padova 35128 Italy (E-mail: adonofrio@hotmail.it).

$0022-5223 / \$ 36.00$

Copyright (c) 2013 by The American Association for Thoracic Surgery

http://dx.doi.org/10.1016/j.jtcvs.2013.06.047
}

expectation and good initial results. Transcatheter aortic valve replacement (TAVR) has been proposed as an alternative treatment of high-risk or inoperable patients with SSAVS. To date, its clinical and hemodynamic results, reported in both prospective studies and national registries, have been good. ${ }^{2-5}$ More recently, sutureless aortic valve replacement (SU-AVR) was developed with the aim of reducing the aortic crossclamp times and facilitating minimally invasive access. ${ }^{6}$ SU-AVR is particularly indicated for patients with multiple comorbidities who would benefit from reduced operative times. Surgeons currently have a variety of methods for treating SSAVS, depending on a patient's risk stratification: SAVR for most patients, TAVR for high-risk or inoperable patients, and SU-AVR for medium- or high-risk operable patients. Our group recently published a propensity-matched study comparing transapical TAVR (TA-TAVR) and SU-AVR showing that, in select patients, SU-AVR is as safe and effective as TA-TAVR. SU-AVR was also associated with a lower incidence of paravalvular leak. ${ }^{7}$ That report was presented at the American Association for Thoracic Surgery 92nd Annual Meeting in 2012, and, during the conference discussion, the 


\begin{tabular}{|c|c|}
\hline \multicolumn{2}{|c|}{ Abbreviations and Acronyms } \\
\hline $\mathrm{AR}$ & $=$ aortic regurgitation \\
\hline OHS & $=$ open-heart surgery \\
\hline PARTNER & $\begin{array}{l}=\text { Placement of Aortic Transcatheter } \\
\text { Valve }\end{array}$ \\
\hline SAVR & $=$ surgical aortic valve replacement \\
\hline SSAVS & $\begin{array}{l}=\text { severe symptomatic aortic valve } \\
\text { stenosis }\end{array}$ \\
\hline SU-AVR & $=$ sutureless aortic valve replacement \\
\hline TA-TAVR & $\begin{aligned}= & \text { transapical transcatheter aortic valve } \\
& \text { replacement }\end{aligned}$ \\
\hline TAVR & $=$ transcatheter aortic valve replacement \\
\hline
\end{tabular}

need for a comparison with a third matched group that included SAVR patients emerged. Therefore, we decided to update our previous study, including SAVR into the analysis. ${ }^{7}$ The aim of the present multicenter, propensitymatched study was to compare the clinical and hemodynamic outcomes of SAVR, TA-TAVR, and SU-AVR.

\section{METHODS}

The ethics committees approved the present study, and patient informed consent for data collection and treatment was always collected.

\section{Transapical Aortic Valve Replacement}

We reviewed the data from 566 patients enrolled in the Italian Registry of Trans-Apical Aortic Valve Implantation from April 2008 through May 2011. The main indication for TA-TAVI was SSAVS (aortic valve area, $<0.8 \mathrm{~cm}^{2}$; mean transaortic gradient, $>40 \mathrm{~mm} \mathrm{Hg}$ ) associated with 1 or more of the following: (1) porcelain aorta; (2) high surgical risk (logistic Euroscore I, $>20 \%$; Society of Thoracic Surgeons mortality score, $>10 \%$ ); and (3) other serious comorbidities, including severe pulmonary disease, previous total chest irradiation, hostile chest, or severe liver disease. TA-TAVI procedures were usually performed with the patient under general anesthesia, and the only implanted devices were the SAPIEN or SAPIEN XT pericardial balloon expandable bioprosthesis (Edwards LifeSciences, Irvine, Calif). The absolute contraindications for TA-TAVI were left ventricular aneurysm with or without thrombotic stratification and an extremely poor left ventricular ejection fraction $(<15 \%)$. More details about the Italian Registry of Trans-Apical Aortic Valve Implantation registry, participating centers and investigators, device characteristics, sizing and surgical technique, postoperative medications, and data collection and analysis have been previously reported. ${ }^{8}$

\section{Sutureless Aortic Valve Replacement}

We prospectively collected and analyzed the data from 38 patients who had undergone isolated SU-AVR with the Perceval S bioprosthesis (Sorin Biomedica Cardio, Saluggia, Italy) at 3 Italian centers from March to September 2011. Details about that cohort of patients and the structural and technical features of the Perceval sutureless bioprosthesis have been described in our previous report. ${ }^{7}$ The indications for SU-AVR were as follows: SSAVS (aortic valve area, $<0.8 \mathrm{~cm}^{2}$; mean transaortic gradient, $>40 \mathrm{~mm} \mathrm{Hg}$ ) and a high surgical risk profile, including advanced age ( $>75$ years), comorbidities, and patient frailty. The exclusion criteria for the use of a Perceval S valve were previous implantation of a valve prosthesis or annuloplasty ring not replaced by the sutureless bioprosthesis, double or multiple valve surgery, aneurysmal dilatation $(\geq 45 \mathrm{~mm})$ or dissection of the ascending aorta, active endocarditis, bicuspid aortic valve, and recent $(<90$ days) myocardial infarction. SU-AVR was performed through a full sternotomy, mini-sternotomy, and mini-right thoracotomy in $23(60.5 \%), 4(10.5 \%)$, and $11(29 \%)$ patients, respectively. Moderate hypothermic $\left(32^{\circ} \mathrm{C}\right)$ cardiopulmonary bypass and transverse aortic crossclamping were used in all patients. Cold-blood cardioplegia was usually administered in an antegrade fashion. Retrograde cardioplegia was used according to surgeon's preferences and the type of approach. The mean aortic crossclamp and cardiopulmonary bypass time was $44 \pm 17$ and $69 \pm 44$ minutes, respectively.

Because no guidelines, position statements, nor recommendations about SU-AVR are available, the choice between TAVR and SU-AVR, especially in high-risk elderly patients, was made by each surgeon individually according to the patient's preoperative characteristics and clinical observation.

\section{Surgical Aortic Valve Replacement}

We retrospectively collected data from 349 consecutive patients who had undergone isolated SAVR from January 2009 through December 2011 at the University of Padova. We collected data from SAVR patients specifically for the present study using exactly the same data set and definitions used for the SU-AVR and TA-TAVR patients. Data were obtained directly from an ad hoc review of the official hospital medical charts and not from already existing databases. All SAVR procedures were performed through full sternotomy, with moderate hypothermic cardiopulmonary bypass. Cold-blood cardioplegia was usually administered in both an antegrade and a retrograde fashion. Prostheses were implanted with 2-0 braided pledgeted horizontal mattress sutures (pledgets on the ventricular side). Bioprostheses and mechanical prostheses were used in $332(95.1 \%)$ and $17(4.9 \%)$ patients, respectively. The mean aortic crossclamp and cardiopulmonary bypass time was $93 \pm 27$ and $124 \pm 33$ minutes, respectively.

The patients in all groups underwent clinical and echocardiographic assessment at the study site before the procedure and at hospital discharge. Echocardiographic measurements were done according to the current recommendations. ${ }^{9}$ Prosthetic aortic regurgitation (AR) was classified as none or trace, mild $(1+/ 3+)$, moderate $(2+/ 3+)$, or severe $(3+/ 3+)$ according to recent recommendations. ${ }^{10}$

\section{Risk Factors and Endpoints}

The preoperative risk factors were defined according to the Euroscore I classification, ${ }^{11}$ and the postoperative outcomes and endpoints were defined according to the Valve Academic Research Consortium definitions. ${ }^{12}$ The recently updated Valve Academic Research Consortium 2 definitions ${ }^{13}$ were not available at the data analysis. The patients were classified as receiving TA-TAVR or "open-heart surgery" (OHS: SUAVR or SAVR). The database records 10 variables: age, gender, body surface area, logistic Euroscore I, New York Heart Association functional class, left ventricular ejection fraction, concomitant mitral valve disease, chronic obstructive pulmonary disease, peripheral vascular disease, and aortic valve area. The dependent variable was a categorical variable comparing the results of the TAVR technique with those of the OHS technique. Within OHS, we further analyzed the results of TA-TAVR versus SU-AVR and TA-TAVR versus SAVR. Our primary study endpoints, defined before analysis, were all-cause 30-day mortality, disabling stroke, permanent pacemaker implantation, renal replacement therapy, periprocedural acute myocardial infarction (within 72 hours after the index procedure), AR at discharge $(\geq 1+/ 3+)$, and the transaortic gradient at discharge.

\section{Statistical Analysis}

Statistical analysis was performed using Stata, version 12.1 (StataCorp, College Station, Tex). The preoperative demographic risk-related variables 
and postoperative (30-day) mortality and morbidity outcomes were investigated. Categorical variables are expressed as frequencies and were compared using the Fisher exact and chi-square tests. Continuous variables are expressed as the mean \pm standard deviation and were compared using the unpaired $t$ test.

Standardized differences were used to assess the degree of baseline variable balance using a well-validated technique. ${ }^{14}$ We estimated the propensity score of the treatment category based on our 10 variables using a logit model and a default $P$ value of .01 . The balancing property was satisfied stratifying 953 of the original patients in 17 blocks. ${ }^{15}$ Subsequently, a 1:1 match on the propensity score, without replacement, was performed using the psmatch 2 procedure, ${ }^{16}$ with a conservative caliper width of $20 \%$ of the standard deviation of the log of propensity score. ${ }^{17}$ A total of 286 patients were successfully matched (143 TA-TAVR and 143 OHS). The psmatch 2 common support option also retained 347 unmatched TAVR patients. In these patients, the matching weight was missing; therefore, we calculated a weight proportional to the inverse of their inclusion probability within their original stratification block. The statistical significance of the results was robust to several different weight specifications. Comparisons between groups were performed considering the matched nature of the propensity score-matched sample. In particular, the paired $t$ test or Wilcoxon signed rank test was used for continuous variables and the McNemar test for binary (dichotomous) variables. A multivariable logistic analysis of the odds ratio of mortality and morbidity was finally performed on the 633 patients in the common support region, adjusting for the SU-AVR and SAVR technique, preoperative covariates, and propensity score. For this purpose, a weighted logistic model, saturated with event-related variables and propensity score inclusion, was used.

\section{RESULTS}

A total of 286 patients were successfully matched: 143 underwent TA-TAVR and 143 underwent OHS. Also, 633 patients were included in the common support region of the propensity analysis. The preoperative clinical characteristics of the patients in the OHS and TA-TAVR cohorts are listed in Tables 1 through 3, which listed the unmatched cohorts, the cohorts after matching in the common support region, and the cohorts after caliper matching, respectively. In the unmatched cohort (Table 1), the TA-TAVR patients were older $(80.6 \pm 6.8$ vs $72.7 \pm 10.1$ years; $P<.001)$ and had a significantly greater logistic Euroscore $(25.5 \% \pm 15 \%$ vs $14.2 \% \quad \pm 11.2 \%$; $P<.001)$. The TA-TAVR patients also had a worse New York Heart Association functional class and were more likely to have peripheral vascular disease $(51.2 \%$ vs $36.7 \% ; P<.001)$ and chronic obstructive pulmonary disease $(35.7 \%$ vs $20.9 \% ; P<.001)$. After matching the 2 cohorts, they were similar in terms of body surface area, logistic Euroscore left ventricular ejection fraction, peripheral vascular disease, and chronic obstructive pulmonary disease. Even after matching, age continued to be significantly different among the cohorts. However, because age is an important component of the logistic Euroscore we were confident that multivariate logistic regression adjusted for this residual imbalance in the observed baseline covariates. Table 4 lists the study endpoints in the 633 patients matched in the common support region. The 30 -day overall mortality was significantly
TABLE 1. Characteristics of patient cohorts before matching

\begin{tabular}{lccc}
\hline \multicolumn{1}{c}{ Variable } & OHS $(\mathbf{n = 3 8 7 )}$ & $\begin{array}{c}\text { TA-TAVR } \\
(\mathbf{n}=\mathbf{5 6 6})\end{array}$ & $\boldsymbol{P}$ value \\
\hline Age $(\mathrm{y})$ & $72.7 \pm 10.1$ & $80.6 \pm 6.8$ & $<.001$ \\
BSA $\left(\mathrm{m}^{2}\right)$ & $1.8 \pm 0.2$ & $1.7 \pm 0.2$ & $<.001$ \\
Logistic Euroscore $(\%)$ & $14.2 \pm 11.2$ & $25.5 \pm 15$ & $<.001$ \\
LVEF $(\%)$ & $59.1 \pm 10.6$ & $52.7 \pm 13.6$ & $<.001$ \\
AVAi $\left(\mathrm{cm}^{2} / \mathrm{m}^{2}\right)$ & $0.51 \pm 0.1$ & $0.55 \pm 0.2$ & .001 \\
Male gender $(\%)$ & 48.3 & 40.8 & .02 \\
NYHA class $\geq 3(\%)$ & 33.1 & 83.4 & $<.001$ \\
PVD $(\%)$ & 36.7 & 51.2 & $<.001$ \\
COPD $(\%)$ & 20.9 & 35.7 & $<.001$ \\
MR $(\%)$ & 9.6 & 9.2 & .07 \\
\hline OHS $\%$ Op) & & &
\end{tabular}

OHS, Open-heart surgery (sutureless and surgical aortic valve replacement); $T A-T A V R$, transapical aortic valve replacement; $B S A$, body surface area; $L V E F$, left ventricular ejection fraction; $A V A i$, aortic valve area index; NYHA, New York Hear Association; $P V D$, peripheral vascular disease; $C O P D$, chronic obstructive pulmonary disease; $M R$, mitral regurgitation.

lower in the SAVR than in TA-TAVR group $(8.6 \%$ vs $0.9 \%$, $P=.002$ ), and no difference was found between the SU-AVR and TA-TAVR groups regarding mortality. The causes of death in the TA-TAVR patients were multiorgan failure in 15 patients $(35.7 \%)$, sepsis in 10 patients $(23.8 \%)$, arrhythmias in 6 patients $(14.3 \%)$, renal insufficiency in 2 patients $(4.8 \%)$, severe hemorrhage in 6 patients $(14.3 \%)$, and mesenteric ischemia in 3 patients $(7.1 \%)$. One patient died in the SAVR matched group of multiorgan failure. No deaths were observed in the SU-AVR matched cohort. The TA-TAVR group had significantly lower transaortic gradients than the SAVR group $(10.3 \pm 4.4 \mathrm{~mm} \mathrm{Hg}$ vs $16.5 \pm 5.8 \mathrm{~mm} \mathrm{Hg}$, $P<.001)$, but they had a greater incidence of at least mild $(\geq 1+/ 3+)$ AR $(34.1 \%$ vs $1.8 \% ; P<.001)$. Furthermore, the SAVR group had a lower incidence of postoperative pacemaker implantation $(0.9 \%$ vs $6.1 \% ; P=.018)$ and

TABLE 2. Characteristics of patient cohorts after matching in common support region

\begin{tabular}{lccc}
\hline \multicolumn{1}{c}{ Variable } & OHS $(\mathbf{n}=\mathbf{1 4 3})$ & $\begin{array}{c}\text { TA-TAVR } \\
(\mathbf{n}=\mathbf{4 9 0})\end{array}$ & $\boldsymbol{P}$ value \\
\hline Age $(\mathrm{y})$ & $73.5 \pm 12.6$ & $80.4 \pm 7$ & $<.001$ \\
BSA $\left(\mathrm{m}^{2}\right)$ & $1.8 \pm 0.3$ & $1.7 \pm 0.2$ & .001 \\
Logistic Euroscore $(\%)$ & $18.3 \pm 14.6$ & $24.5 \pm 14.1$ & $<.001$ \\
LVEF $(\%)$ & $58.1 \pm 10.9$ & $53.4 \pm 13.6$ & $<.001$ \\
AVAi $\left(\mathrm{cm}^{2} / \mathrm{m}^{2}\right)$ & $0.55 \pm 0.2$ & $0.54 \pm 0.2$ & .93 \\
Male gender $(\%)$ & 49.7 & 40.8 & .07 \\
NYHA $(\%)$ & 54.5 & 81.2 & $<.001$ \\
PVD $(\%)$ & 37.1 & 48.8 & .17 \\
COPD $(\%)$ & 25.9 & 33.9 & .08 \\
MR $(\%)$ & 24.5 & 68.2 & $<.001$ \\
\hline OHS, Op & &
\end{tabular}

OHS, Open-heart surgery (sutureless and surgical aortic valve replacement); $T A-T A V R$, transapical aortic valve replacement; $B S A$, body surface area; $L V E F$, left ventricular ejection fraction; $A V A i$, aortic valve area index; $N Y H A$, New York Hear Association; $P V D$, peripheral vascular disease; $C O P D$, chronic obstructive pulmonary disease; $M R$, mitral regurgitation. 
TABLE 3. Characteristics of patient cohorts after caliper 1:1 matching

\begin{tabular}{lccc}
\hline \multicolumn{1}{c}{ Variable } & OHS $(\mathbf{n}=\mathbf{1 4 3})$ & $\begin{array}{c}\text { TA-TAVR } \\
(\mathbf{n}=\mathbf{1 4 3})\end{array}$ & $\boldsymbol{P}$ value \\
\hline Age $(\mathrm{y})$ & $73.5 \pm 12.6$ & $77.6 \pm 9$ & .003 \\
BSA $\left(\mathrm{m}^{2}\right)$ & $1.8 \pm 0.3$ & $1.7 \pm 0.2$ & .12 \\
Logistic Euroscore $(\%)$ & $18.3 \pm 14.6$ & $20.2 \pm 12.5$ & .22 \\
LVEF $(\%)$ & $58.1 \pm 10.9$ & $56.1 \pm 13$ & .15 \\
AVAi $\left(\mathrm{cm}^{2} / \mathrm{m}^{2}\right)$ & $0.55 \pm 0.2$ & $0.55 \pm 0.2$ & .93 \\
Male gender $(\%)$ & 49.7 & 37.1 & .03 \\
NYHA $(\%)$ & 54.5 & 65 & .08 \\
PVD $(\%)$ & 37.1 & 42.7 & .43 \\
COPD $(\%)$ & 25.9 & 32.2 & .25 \\
MR $(\%)$ & 24.5 & 32.9 & .06 \\
\hline
\end{tabular}

$O H S$, Open-heart surgery (sutureless and surgical aortic valve replacement); $T A-T A V R$, transapical aortic valve replacement; $B S A$, body surface area; $L V E F$, left ventricular ejection fraction; $A V A i$, aortic valve area index; $N Y H A$, New York Hear Association; $P V D$, peripheral vascular disease; $C O P D$, chronic obstructive pulmonary disease; $M R$, mitral regurgitation.

need for renal replacement therapy $(0 \%$ vs $7.6 \%$; $P=.001)$. No other endpoints were significantly different statistically between the TA-TAVR and SAVR or between the TA-TAVR and SU-AVR groups. The analysis of endpoints in the 286 caliper 1:1 matched patients is listed in Table 5. A difference was still found in mortality between the TA-TAVR and SAVR groups, although the statistical significance was less pronounced than with the analysis of the common support region $(7 \%$ vs $1.8 \% ; P=.026)$. Also, in the 1:1 matched cohort, TA-TAVR demonstrated significantly lower gradients than SAVR $(10.7 \pm 4.4 \mathrm{~mm}$ $\mathrm{Hg}$ vs $16.5 \pm 5.8 \mathrm{~mm} \mathrm{Hg} ; P<.001)$ and a greater incidence of $\operatorname{AR}(28.7 \%$ vs $1.8 \% ; P<.001)$. The multivariate analysis showed that SU-AVR had a protective effect, although the difference was not statistically significant, against AR, pacemaker implantation, and renal replacement therapy compared with TA-TAVR. However, compared with TA-TAVR, SAVR demonstrated significant protection against AR (odds ratio, 0.04; $P<.001$ ) and a trend toward protection against death, pacemaker implantation, and myocardial infarction. The effect of SAVR and SU-AVR on the predefined endpoints, with respect to TA-TAVR, is presented in Table 6.

\section{DISCUSSION}

The complete portfolio of aortic valve substitutes includes SAVR, SU-AVR, and TAVR. The present study is the first to evaluate and compare, with a propensitymatched analysis, the results of all these techniques in patients with SSAVS. Although our study should be considered a preliminary study, it gives some important insights into this contemporary and controversial issue. The main findings of the present study were that SU-AVR and SAVR might potentially have some advantages over TAVR in selected patients. This could have resulted from the patient selection process that occurred in our analysis. The attempt to match these 3 cohorts resulted in selecting the "worse" OHS patients and the "best" TAVR patients. This was clearly shown in Tables 1 through 3, in which the matched TA-TAVR cohort had fewer comorbidities and lower logistic Euroscore values than the unmatched cohort, and the matched SAVR patients had more comorbidities and greater logistic Euroscore values than the unmatched cohort. Thus, as stated in our previous report, these patients belong to a "gray zone," in which an overlap of indications is present for the different procedures. However, even if the 3 groups after matching were similar (especially after 1:1 caliper matching), other factors that could have had a significant effect on patient outcomes, such as frailty, were not considered. It is likely that this -subgroup of patients, who belong to the "gray zone" of surgical risk, were assigned to 1 or the other treatment group on the basis of these unaccounted for conditions. The empiric proportions in Tables 4 and 5 show that the SAVR group had a significantly lower rate of death than did the TA-TAVR group in the matched patients. This seems to be in contrast to the results from the Placement of Aortic Transcatheter Valve (PARTNER) trial ${ }^{3}$ but can be explained by several reasons. The PARTNER trial was a prospective randomized trial with strict inclusion and exclusion criteria and was conducted in select centers that considered both

TABLE 4. Postoperative outcomes after TA-TAVR, SU-AVR, and SAVR; analysis included 633 patients of common support region

\begin{tabular}{|c|c|c|c|c|c|}
\hline \multirow[b]{2}{*}{ Outcome } & \multirow[b]{2}{*}{ TA-TAVR $(n=490)$} & \multirow[b]{2}{*}{ SU-AVR $(n=31)$} & \multirow[b]{2}{*}{$\operatorname{SAVR}(n=112)$} & \multicolumn{2}{|c|}{$P$ value } \\
\hline & & & & TA-TAVR vs SU-AVR & TA-TAVR vs SAVR \\
\hline Death (n) & $42(8.6)$ & 0 & $1(0.9)$ & .16 & $.002 *$ \\
\hline Stroke (n) & $12(2.5)$ & 0 & 0 & 1 & $.14^{*}$ \\
\hline PPM (n) & $30(6.1)$ & $1(3.2)$ & $1(0.9)$ & 1 & $.018^{*}$ \\
\hline RRT (n) & $37(7.6)$ & $1(3.2)$ & 0 & .72 & $.001^{*}$ \\
\hline AMI (n) & $9(1.9)$ & 0 & $1(0.9)$ & 1 & $.70 *$ \\
\hline Postoperative AR $(\geq 1+/ 3+)(\mathrm{n})$ & $167(34.1)$ & $6(19.4)$ & $2(1.8)$ & .12 & $<.001^{*}$ \\
\hline Mean gradient $(\mathrm{mm} \mathrm{Hg})$ & $10.3 \pm 4.4$ & $11.1 \pm 3.4$ & $16.5 \pm 5.8$ & $.36^{*}$ & $<.001 \dagger$ \\
\hline
\end{tabular}

Data in parentheses are percentages. TA-TAVR, Transcatheter aortic valve replacement; $S U$-AVR, sutureless aortic valve replacement; $S A V R$, surgical aortic valve replacement; $P P M$, permanent pacemaker replacement; $R R T$, renal replacement therapy; $A M I$, acute myocardial infarction; $A R$, aortic regurgitation. *Two-tailed Fisher exact test. $\dagger$ Unpaired $t$ test. 
TABLE 5. Postoperative outcomes after TA-TAVR, SU-AVR, and SAVR; analysis included 286 patients with caliper matching 1:1

\begin{tabular}{|c|c|c|c|c|c|}
\hline \multirow[b]{2}{*}{ Outcome } & \multirow[b]{2}{*}{ TA-TAVR $(n=143)$} & \multirow[b]{2}{*}{ SU-AVR $(n=31)$} & \multirow[b]{2}{*}{$\operatorname{SAVR}(n=112)$} & \multicolumn{2}{|c|}{$P$ value } \\
\hline & & & & TA-TAVR vs SU-AVR & TA-TAVR vs SAVR \\
\hline Death (n) & $10(7)$ & 0 & $1(1.8)$ & 0.21 & $.026^{*}$ \\
\hline Stroke (n) & $4(2.8)$ & 0 & 0 & 1 & $.13 *$ \\
\hline PPM (n) & $7(4.9)$ & $1(3.2)$ & $1(0.9)$ & 1 & $.082 *$ \\
\hline RRT (n) & $7(4.9)$ & $1(3.2)$ & 0 & 1 & $.019 *$ \\
\hline AMI (n) & $5(3.5)$ & 0 & $1(0.9)$ & 0.59 & $.23 *$ \\
\hline Postoperative AR $(\geq 1+/ 3+)$ & $41(28.7)$ & $6(19.4)$ & $2(1.8)$ & 0.37 & $<.001 *$ \\
\hline Mean gradient $(\mathrm{mm} \mathrm{Hg})$ & $10.7 \pm 4.4$ & $11.1 \pm 3.3$ & $16.5 \pm 5.8$ & $0.69^{*}$ & $<.001 \dagger$ \\
\hline
\end{tabular}

Data in parentheses are percentages. TA-TAVR, Transcatheter aortic valve replacement; $S U$ - $A V R$, sutureless aortic valve replacement; $S A V R$, surgical aortic valve replacement; $P P M$, permanent pacemaker replacement; $R R T$, renal replacement therapy; $A M I$, acute myocardial infarction; $A R$, aortic regurgitation. *Two-tailed Fisher exact test. †Unpaired $t$ test.

transapical and transfemoral TAVR. In contrast, our study was based on the analysis of data from patients who had undergone surgery in the "real world." We only considered TA-TAVR and not transfemoral TAVR. Furthermore, the patient characteristics were different from those in the PARTNER trial; in particular, the logistic Euroscore of the PARTNER SAVR patients was $29 \%$, but in our study, it was $18 \%$ (also including the SU-AVR patients), and this could explain the different 30-day mortality rate between these 2 studies (PARTNER, 6.5\%; our study, $0.9 \%$ ). However, the power of the test in the $1: 1$ match was $46 \%$, and on multivariate analysis, TA-TAVR was not found to be an independent predictor of mortality; thus, this result should be interpreted with caution.

Even if the rate of AR in the SU-AVR patients seems high $(19 \%)$, one should consider that all the leaks were mild $(1+/ 3+)$, that this incidence was similar to that in other series, ${ }^{18}$ and that these results were from surgeons' early experience using this new technique, with learning curverelated issues. On multivariate analysis, SU-AVR seemed to reduce the risk of postoperative $A R$, permanent pacemaker implantation, and renal replacement therapy compared with TA-TAVR. However, the only statistically

TABLE 6. Postoperative clinical outcomes after matching and multivariate analysis

\begin{tabular}{|c|c|c|c|c|}
\hline Outcome & $\begin{array}{c}\text { SU-AVR vs } \\
\text { TA-TAVR OR }\end{array}$ & $P$ value* & $\begin{array}{c}\text { SAVR vs } \\
\text { TA-TAVR OR }\end{array}$ & $P$ value $*$ \\
\hline Death & 1.00 & - & 0.23 & .17 \\
\hline $\begin{array}{l}\text { Postoperative } \\
\qquad \operatorname{AR}(\geq 1+/ 3+)\end{array}$ & 0.55 & .23 & 0.04 & $<.001$ \\
\hline Stroke & 1.00 & - & 1.00 & - \\
\hline PM implantation & 0.51 & .53 & 0.97 & .14 \\
\hline RRT & 0.61 & .68 & 1.00 & - \\
\hline AMI & 1.00 & - & 0.38 & .47 \\
\hline $\begin{array}{l}\text { Mean gradient } \\
\text { at discharge }\end{array}$ & 1.02 & .56 & 1.19 & $<.001$ \\
\hline
\end{tabular}

significant difference was in the reduction of $A R$ in the SAVR patients compared with that in the TA-TAVR patients. Postoperative AR is a highly debated issue, especially after the results of the PARTNER trial at 2 years showed that even a mild degree of AR significantly worsens patient survival. ${ }^{19}$ The reason for an AR reduction after SU-AVR was mainly because of the "open heart" implantation of sutureless valves, which enabled the surgeon to remove valve leaflets and annular calcifications and to directly measure the aortic annulus to choose the most appropriate prosthesis size. Furthermore, the prosthesis is implanted under direct vision; thus, if the final result is not satisfactory, the valve can be removed and repositioned either during the same aortic clamping or with a second aortic clamping if the leak is discovered using intraoperative transesophageal echocardiography. ${ }^{20}$ The presence and distribution of calcium within the aortic annulus has been demonstrated to predict AR after TAVR $^{21}$; thus, its removal could have an affect on reducing postoperative AR after SAVR. All these mechanisms also explain the advantage of SAVR over TAVR in the reduction of the risk of AR. Postoperative AR is still a major issue that must be solved before TAVR indications can be expanded toward a lower risk patient population. Another important issue related to TAVR is the rate of postoperative permanent pacemaker implantation. Although self-expandable devices were associated with a significantly greater incidence of pacemaker implantation than balloon-expandable valves, ${ }^{22}$ a significant advantage was still found for "open-heart" devices compared with TAVR. The "blind" lateral displacement of aortic annulus calcifications that occurs during TAVR (during both balloon aortic valvuloplasty and valve deployment), rather than their "surgical" removal, such as is usually performed in SU-AVR and SAVR, could explain the greater incidence of conduction tissue injuries. We also found that TA-TAVR patients had significantly lower gradients than those receiving "open-heart" devices. The hemodynamic behavior of transcatheter valves was therefore better than that of conventional aortic prostheses. However, future larger 
studies with longer follow-up are necessary to demonstrate whether these differences have a significant clinical effect. With the present study, we wish to highlight that surgical aortic valve replacement is still the best choice for patients with aortic valve stenosis. However, new therapeutic options such as TAVR and SU-AVR can provide good results in select patients. A center that is able to offer their patients all these therapeutic alternatives can select the most appropriate technique, tailoring the choice to each patient and considering all crucial characteristics such as age, comorbidities, frailty, and anatomy. A particularly careful evaluation is needed for patients in the "gray zone," who can benefit from either technique. An experienced "aortic team" will be able to make the most appropriate choice. The limitations of the present study were mainly related to the retrospective nature, the different procedures conducted at different centers, the inclusion of TATAVR-only patients, and the small number of patients in the SU-AVR cohort.

In conclusion, our data have shown that no main differences exist in the outcomes among SAVR, TA-TAVR, and SU-AVR. SAVR was associated with a significant reduction in postoperative AR compared with TA-TAVR. The latter, however, showed lower transaortic gradients. A trend was seen toward less AR in the SU-AVR group than in the TA-TAVR group; however, this difference was not statistically significant. Future, larger, and, possibly, prospective studies are needed to confirm our preliminary results.

The authors are grateful to Leila Hosseinian, MD, and Gianluca Torregrossa, MD, for their kind and precious assistance in language editing and manuscript revision.

\section{References}

1. Svensson LG, Adams DH, Bonow RO, Kouchoukos NT, Miller DC, O'Gara PT, et al. Aortic valve and ascending aorta guidelines for management and quality measures: executive summary. Ann Thorac Surg. 2013;95:1491-505.

2. Leon MB, Smith CR, Mack M, Miller DC, Moses JW, Svensson LG, et al. Transcatheter aortic valve implantation for aortic stenosis in patients who cannot undergo surgery. N Engl J Med. 2010;363:1597-607.

3. Smith CR, Leon MB, Mack M, Miller DC, Moses JW, Svensson LG, et al. Transcatheter versus surgical aortic valve replacement in high-risk patients. $N$ Engl J Med. 2011;364:2187-98.

4. Gilard M, Eltchaninoff H, Iung B, Donzeau-Gouge P, Chevreul K, Fajadet J, et al. Registry of transcatheter aortic-valve implantation in high-risk patients. $N$ Engl J Med. 2012;366:1705-15.

5. Beckmann A, Hamm C, Figulla HR, Cremer J, Kuck KH, Lange R, et al. The German Aortic Valve Registry (GARY): a nationwide registry for patients undergoing invasive therapy for severe aortic valve stenosis. Thorac Cardiovasc Surg. 2012;60:319-25.

6. Santarpino G, Pfeiffer S, Fischlein T. Sutureless aortic valve replacement to prevent patient-prosthesis mismatch in the era of valve-in-valve implantation. J Thorac Cardiovasc Surg. 2012;144:279-80.

7. D’Onofrio A, Messina A, Lorusso R, Alfieri OR, Fusari M, Rubino P, et al. Sutureless aortic valve replacement as an alternative treatment for patients belonging to the "gray zone" between transcatheter aortic valve implantation and conventional surgery: a propensity-matched, multicenter analysis. J Thorac Cardiovasc Surg. 2012;144:1010-6.

8. D’Onofrio A, Rubino P, Fusari M, Salvador L, Musumeci F, Rinaldi M, et al. Clinical and hemodynamic outcomes of "all-comers" undergoing transapical aortic valve implantation: results from the Italian Registry of Trans-Apical Aortic Valve Implantation (I-TA). J Thorac Cardiovasc Surg. 2011;142:768-75.

9. Lang RM, Bierig M, Devereux RB, Flachskampf FA, Foster E, Pellikka PA, et al. Recommendations for chamber quantification. Eur J Echocardiogr. 2006;7: 79-108.

10. Zoghbi WA, Chambers JB, Dumesnil JG, Foster E, Gottdiener JS, Grayburn PA, et al. Recommendations for evaluation of prosthetic valves with echocardiography and Doppler ultrasound: a report from the American Society of Echocardiography's Guidelines and Standards Committee and the Task Force on Prosthetic Valves, developed in conjunction with the American College of Cardiology Cardiovascular Imaging Committee, Cardiac Imaging Committee of the American Heart Association, the European Association of Echocardiography, a registered branch of the European Society of Cardiology, the Japanese Society of Echocardiography and the Canadian Society of Echocardiography, endorsed by the American College of Cardiology Foundation, American Heart Association, European Association of Echocardiography, a registered branch of the European Society of Cardiology, the Japanese Society of Echocardiography, and Canadian Society of Echocardiography. J Am Soc Echocardiogr. 2009;22:975-1014.

11. Nashef SA, Roques F, Michel P, Gauducheau E, Lemeshow S, Salamon R. European system for cardiac operative risk evaluation. Eur J Cardiothorac Surg. 1999;16:9-13.

12. Leon MB, Piazza N, Nikolsky E, Blackstone EH, Cutlip DE, Kappetein AP, et al. Standardized endpoint definitions for transcatheter aortic valve implantation clinical trials. J Am Coll Cardiol. 2011;57:253-69.

13. Kappetein AP, Head SJ, Généreux P, Piazza N, van Mieghem NM, Blackstone EH, et al. Updated standardized endpoint definitions for transcatheter aortic valve implantation: the Valve Academic Research Consortium-2 consensus document. Eur Heart J. 2012;33:2403-18.

14. Austin PC. Propensity-score matching in the cardiovascular surgery literature from 2004 to 2006: a systematic review and suggestions for improvement. J Thorac Cardiovasc Surg. 2007;134:1128-35.

15. Becker SO, Ichino A. Estimation of average treatment effects based on propensity scores. Stata J. 2002;2:358-77.

16. Leuven E, Sianesi B. PSMATCH2: Stata module to perform full Mahalanobis and propensity score matching, common support graphing, and covariate imbalance testing, version 4.0.5. 2003. Available at: http://ideas.repec.org/c/ boc/bocode/s432001.html. Accessed April 18, 2013.

17. Guo S, Fraser MW. Propensity score analysis: statistical methods and applications. Psychometrika. 2010;75:775-7.

18. Flameng W, Herregolds MC, Hermans H, Van der Mieren G, Vercalsteren M, Poortmans G, et al. Effect of sutureless implantation of the Perceval S aortic valve bioprosthesis on intraoperative and early postoperative outcomes. J Thorac Cardiovasc Surg. 2011;142:1453-7.

19. Kodali SK, Williams MR, Smith CR, Svensson LG, Webb JG, Makkar RR, et al. Two-year outcomes after transcatheter or surgical aortic-valve replacement. N Engl J Med. 2012;366:1686-95.

20. Shrestha M, Folliguet T, Meuris B, Dibie A, Bara C, Herregods MC, et al. Sutureless Perceval S aortic valve replacement: a multicenter, prospective pilot trial. J Heart Valve Dis. 2009;18:698-702.

21. Colli A, D'Amico R, Kempfert J, Borger MA, Mohr FW, Walther T, et al. Transesophageal echocardiographic scoring for transcatheter aortic valve implantation: impact of aortic cusp calcification on postoperative aortic regurgitation. J Thorac Cardiovasc Surg. 2011;142:1229-35.

22. Ledwoch J, Franke J, Gerckens U, Kuck KH, Linke A, Nickenig G, et al. Incidence and predictors of permanent pacemaker implantation following transcatheter aortic valve replacement: analysis from the German Transcatheter Aortic Valve Interventions Registry [epub ahead of print]. Catheter Cardiovasc Interv. 2013 Mar 8; doi: 10.1002/ccd.24915.

\section{Discussion}

Dr Martin Misfeld (Leipzig, Germany). I would like to thank the American Association for Thoracic Surgery (AATS) for the opportunity to discuss the report by Dr D'Onofrio and colleagues and Dr D'Onofrio for supplying me with the report in a timely manner.

The present study is a comparison of 566 patients undergoing TA-TAVR in 20 Italian cardiac surgery centers and 38 patients undergoing SAVR in 3 centers and 349 patients undergoing 
conventional aortic valve replacement in 1 center. It represents an extension of a study presented at last year's AATS meeting and has recently been published in the Journal of Thoracic and Cardiovascular Surgery, in which comparisons were made between patients receiving a transapical Edwards SAPIEN valve and those who underwent implantation of the Perceval S sutureless valve. To the best of my knowledge, the present report is the first to compare these 3 patient groups simultaneously.

Dr D'Onofrio and colleagues have used sophisticated propensity score matching to compare these 3 groups. However, the overlapping treatment period of the 3 patient groups and the lack of randomization very likely resulted in significant differences among the groups. The patient factors that were not measured, such as frailty, porcelain aorta, or other risk factors for conventional surgery, were undoubtedly different among the groups. Although these unmeasured patient factors could explain the elevated mortality observed in the TAVR group, they are less likely to have affected the observed hemodynamic differences among the groups (ie, the lower transvalvular gradient and greater incidence of AR in the TAVR group).

I have 4 questions for the authors.

First, what were the criteria for deciding whether patients underwent TA-TAVR or sutureless valve implantation in the elderly high-risk subgroup and what patient-related features would have made you decide that 1 technique would be definitely more suitable than the other?

Second, the paravalvular leak rate for the sutureless group was greater than that usually mentioned in published studies. Do you have an explanation for this?

Third, did the sutureless valve patients have lower crossclamp and cardiopulmonary bypass times than those undergoing conventional AVR?

Finally, is it time for a randomization trial between sutureless valves and TAVR?
Once again, I would like to thank the Association for the honor of being able to discuss this unique and important study.

Dr D'Onofrio. Thank you for your kind comments and questions.

Talking about your first question, actually, each of these techniques has pros and cons for high-risk patients. I'm talking about transcatheter and sutureless aortic valve replacement.

Transcatheter is, of course, less invasive. It can be performed on the awake patient, especially if performed through transfemoral access, and does not require cardiopulmonary bypass or aortic crossclamping; thus, it is definitely less invasive. However, the rate of paravalvular leak is still high.

In contrast, SAVR requires cardiopulmonary bypass and aortic crossclamping. With this technique, the hemodynamic results in terms of paravalvular leakage have been much better.

I think that the choice between these 2 alternative techniques should be tailored to the characteristics of each patient, considering age, comorbidities, and, as you mentioned, frailty and other factors that usually are not included in risk scores.

Regarding the incidence of paravalvular leak, it was high in the sutureless group, that is true, but even mild AR was included in these analyses. The patients with mild AR were actually the first 30 patients who received the sutureless valve in our country. It was at the very beginning of the learning curve. Currently, we have been observing a progressive decrease in paravalvular leakage as our experience in sizing and the implantation technique has improved.

The crossclamp and cardiopulmonary bypass time was 44 minutes and 69 minutes, respectively, in the sutureless group. Again, this was the very beginning of our experience, and we now are observing that the crossclamp time in these patients can be as low as 20 minutes with the improvement in experience.

Of course, a trial would be an excellent idea. However, as you mentioned, these are 3 techniques for 3 different groups of patients. Thus, it would not be easy to design a prospective study to include all 3 techniques in similar patients. 